\title{
Harmfulness Defect in Double-Notched Specimen of S533 Steel
}

\author{
Ouhimmou Siham, Hachim Abdelilah, Salmi Houda
}

\begin{abstract}
The analytical solving of fracture mechanics equations remains insufficient for complex mechanisms, hence the use of finite element methods (FEM). The paper considered a test specimen with double S355 steel notches, stressed in tension, causing crack opening with two planes of symmetry. The refinement of the mesh is carried out at the bottom of the notch using the elements of Barsoum. The stress concentration coefficient and the crack propagation velocity are evaluated.
\end{abstract}

Keywords: Double notch, S355 stell, FEM, Barsoum, crack propagation.

\section{INTRODUCTION}

To meet ever higher performance requirements, manufacturers must at best anticipate the presence of structural defects in their actual operating conditions. In this context, the majority of failures in pressure equipment are due to stress concentrations in the vicinity of a defect. The understanding of this phenomenon involves the numerical modeling of the structure but the analytical resolution of the resulting equations remains limited to simple problems whereas in reality there are complex mechanisms.

the harmfulness of the defaults is measured in elasticity by the stress intensity factor and in elasto-plasticity by the integral of contour $\mathrm{J}$; scientific research is concerned with numerical simulations by classical methods based on the finite element method (FEM) coupled with the mechanics of fracture [1,2]. EL HAKIMI [3] has generalized the study of the problems of cracks to cylindrical and spherical pressure shell, his approach is based on stress intensity factors and the integral of Rice. TOPPER and EL HADDAD [4] used the stress distribution at the head of a short fissure emanating from a notch, to establish the boundary conditions between the theoretical stress concentration factor of a blunt notch and that of a crack. Acute cut, RAHMAN and BRUST [5] have shown that the integral $\mathrm{J}$ is the parameter of the fracture mechanics that characterizes the initiation of propagation and

Revised Manuscript Received on April 27, 2020.

* Correspondence Author

Ouhimmou Siham *, Laboratoire de mécanique, université hassan II, Faculté des Sciences Aïn Chock, Km 8 Route d'El Jadida B.P 5366, Maarif Casablanca

Hachim Abdelilah, Institut Supérieur d'Etudes Maritimes (ISEM) Km 7 , Route d'El Jadida

Salmi Houda, National Higher School of Electricity and Mechanics, Laboratory of Control and Mechanical Characterization of Materials and Structures, Casablanca, Morocco.

(C) The Authors. Published by Blue Eyes Intelligence Engineering and Sciences Publication (BEIESP). This is an open access article under the CC BY-NC-ND license (http://creativecommons.org/licenses/by-nc-nd/4.0/) the instability of cracks in ductile materials. All this work and many others have shown the need to use numerical methods given the complexity of the stress field at the level of defects in pressure equipment.The industrial objectives of the paper are the determination of the harmfulness of the defects studied and the application of the numerical tools validated experimentally.

In the first part of this work, we considered a material mainly used in pressure equipment, we modeled a specimen with double lateral notches, stressed in tension, causing crack opening. The stress concentration coefficient and the cracking rate for the two-dimensional model have been calculated and compared with the experimental results.

\section{NUMERICAL STUDY}

The use of numerical methods is becoming more common because of their low cost and speed. This intense use is encouraged by the possibility of integrating in the numerical code precise descriptions of phenomena such as constitutive laws and breaking criteria and this is possible even for complex structures.

The numerical study presented in this part is dedicated to the study of the influence of double-notch specimen defects, as well as the comparison of the results resulting from this study with those of the experimental results.

\section{A. Studied model}

We consider a specimen with double lateral notches, stressed in tension (in mode I), causing an opening of the crack. The geometric model of the specimens used for the experiment was discretized by finite elements in order to compare the results.

The numerical simulation is carried out using the CASTEM structures calculation code [6]. For this first validation step, the geometry is retained identical to that of the experiment, it is given by Fig.1

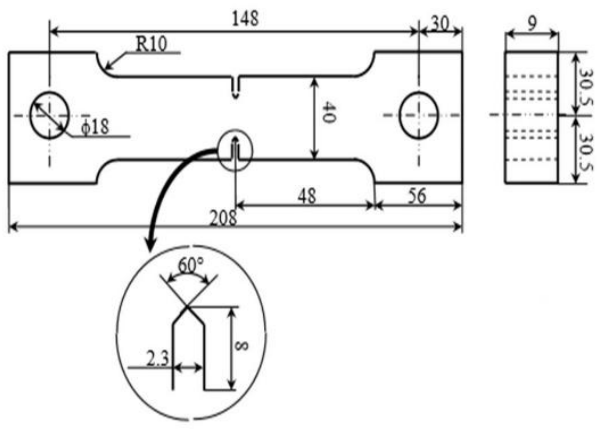

Fig.1: Dimensions of a double-notched specimen in (mm) 


\section{B. Material}

The material used in the test program is S355 steel, its chemical composition is reported in Table 1 [8]:

Table I: Chemical composition of the S355 steel specimen

\begin{tabular}{|l|l|l|l|l|l|l|}
\hline & \multicolumn{6}{|c|}{ Composition \% } \\
\hline S355 & $\mathrm{C}$ & $\mathrm{Mn}$ & $\mathrm{P}$ & $\mathrm{S}$ & $\mathrm{Si}$ & $\mathrm{Cu}$ \\
\cline { 2 - 7 } & 0.29 & $0.80-1.20$ & 0.09 & 0.05 & $1.15-0.30$ & 20 \\
\hline
\end{tabular}

The static tensile tests were carried out on four smooth test pieces. These average results are reported in Table 2.

Table II: Mechanical Properties of the S355 Steel Specimen [7]

\begin{tabular}{|l|l|l|l|}
\hline $\begin{array}{l}\text { Youngs } \\
\text { Modulus }\end{array}$ & $\begin{array}{l}\text { "Poisson's } \\
\text { coefficient }\end{array}$ & Yield stress & $\begin{array}{l}\text { Ultimate } \\
\text { stress }\end{array}$ \\
\hline $200 \mathrm{GPa}$ & 0.3 & $372 \mathrm{MPa}$ & $621 \mathrm{MPa}$ \\
\hline
\end{tabular}

\section{Meshing and boundary conditions}

We model the elastic behavior of the material. The test piece has two planes of symmetry and therefore only a quarter of the test piece is modeled. The model has 4980 elements of cubic type with 8 nodes.
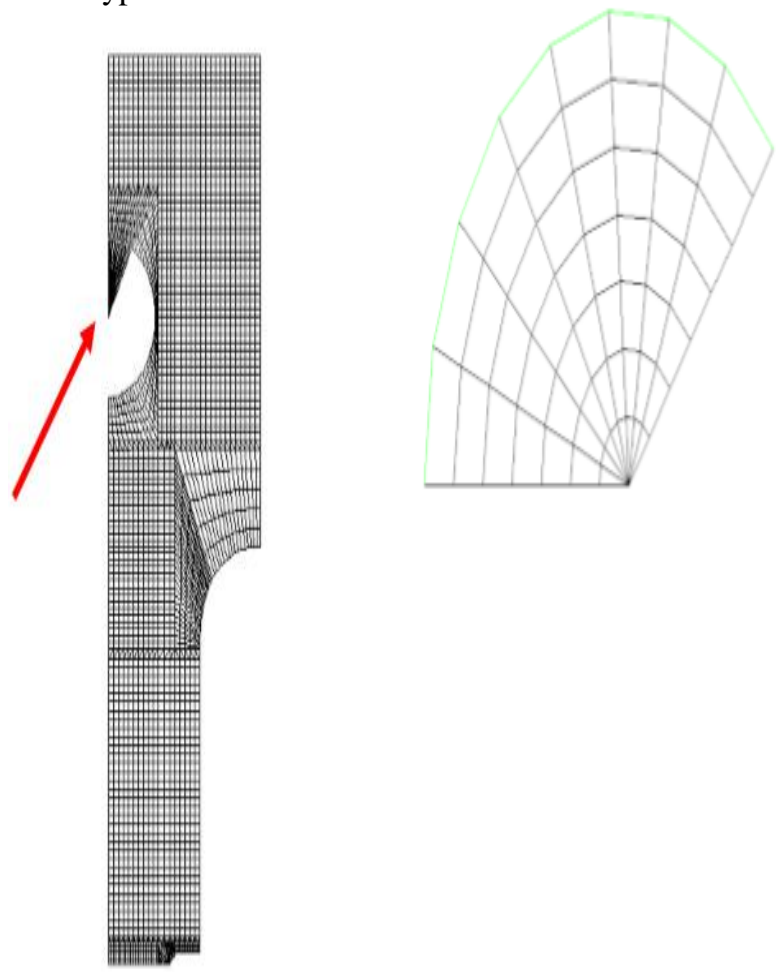

Figure 2 -a: Meshing of a Figure 2-b: Meshing near the quarter of the test piece notch

The expected results are intended for a mechanical analysis of the fracture, therefore special care is given at the bottom of the notch (refined mesh / Barsoum elements) as shown in Figures 2-a and 2-b.

\section{Loading}

The simulated loading is a tensile stress along the longitudinal axis of the specimen. In order to avoid any bending or parasitic torsion and to make sure that the tensile stress is perfectly in the axis, the loading is applied on the specimen by means of a rigid triangle indicated by the arrow of the Figure 2-a. The nominal stresses applied are respectively $352 \mathrm{MPa}$, 282MPa and 248MPa.

\section{RESULTS AND DISCUSSIONS}

For each solicitation, we advance the crack numerically by simple incrementation. For each increment of crack, we calculate the associated $\Delta \mathrm{K} 1$ by the G-THETA method. We presented the curves of progress of crack according to $\Delta \mathrm{K} 1$. By applying the law of Paris with $C=3.6 \times 10-10$ and $\mathrm{m}=3$, we have numerically determined the crack velocity curve as a function of its crack length.

\section{Stress distribution in 2 dimensions}

We check that the stress reaches its maximum at the bottom of the notch and that the nominal stress is equal to the applied stress. Table 3 gives the numerical values of $\sigma \mathrm{Max}$ and $\sigma$ nom for the following three applied $\Delta \sigma$ constraints: $352 \mathrm{MPa}$, 282MPa and 248MPa.

Table. III: Numerical values of the maximum stress and the nominal stress as a function of the stress applied

\begin{tabular}{|l|l|l|}
\hline$\Delta \sigma(\mathrm{MPa})$ & $\Delta \sigma \max (\mathrm{MPa})$ & $\Delta \sigma$ nom(MPa) \\
\hline 352 & 1764 & 352 \\
\hline 282 & 1417 & 282 \\
\hline 248 & 1247 & 248 \\
\hline
\end{tabular}

Where, $\Delta \sigma:$ Applied stress бmax : Numerical maximum stress onom : Numerical nominal stress

The maximum stress and the nominal stress increases when the applied stress increases, the applied stress $(\Delta \sigma)$ is equal to the nominal stress ( $\sigma$ nom). The concordance of the numerical values with the theory validate our numerical study.

\section{B. Stress concentration coefficient $\mathrm{Kt}$ in $\mathbf{2}$ dimensions}

In order to quantify the importance of the local stress increase, we calculated the values of the numerical stress concentration coefficient Ktnum along the axis of the spacemen by the Peterson relationship [8] according to Eq.(1).

$\mathrm{Kt}=\sigma \mathrm{max} / \sigma \mathrm{nom}$

The numerical value of the stress concentration coefficient Kt for the applied stresses $(\Delta \sigma=352 \mathrm{MPa}, 282 \mathrm{MPa}, 248 \mathrm{MPa})$ in $2 \mathrm{D}$ is the same, $\mathrm{Kt}=5$.

the value of the numerical $\mathrm{Kt}$ agrees with $\mathrm{Kt}$ found experimentally [9]. The small value of the notch radius $(<0.2 \mathrm{~mm})$ and its angle of $60^{\circ}$ make the value of the stress concentration coefficient Kt high.

C. Evolution of the normal stress along the horizontal axis of the specimen for the two-dimensional model

The curves of FIGS. (3-5) show the evolution of the numerical stress along the horizontal axis of the sample for the three applied stresses namely: $\Delta \sigma=352 \mathrm{MPa}, 282 \mathrm{MPa}$, $248 \mathrm{MPa}$.

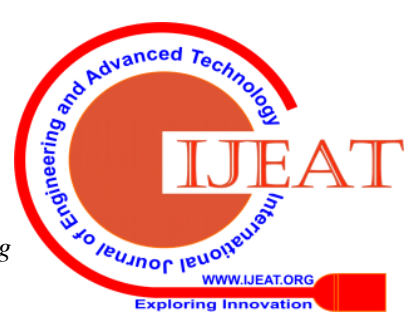




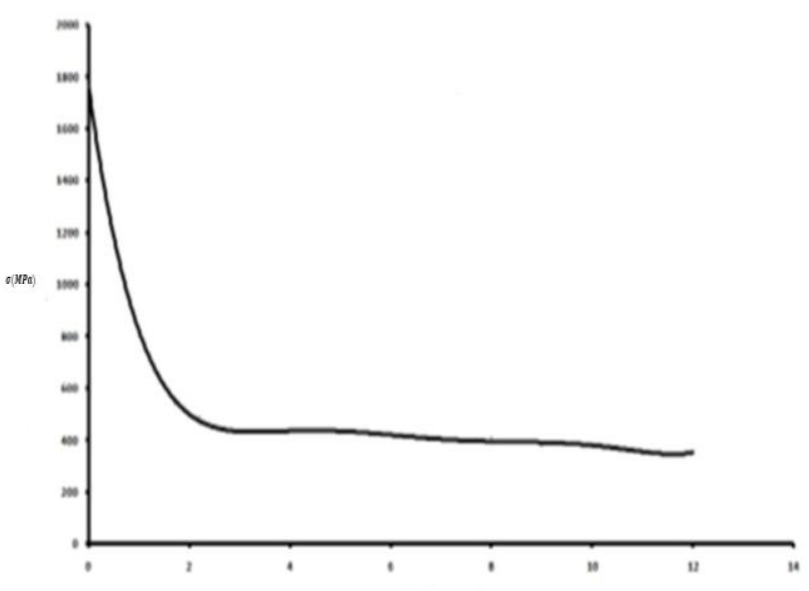

Fig. 3: Evolution of the numerical stress along the horizontal axis of the specimen, $\Delta \sigma=282 \mathrm{MPa}$.

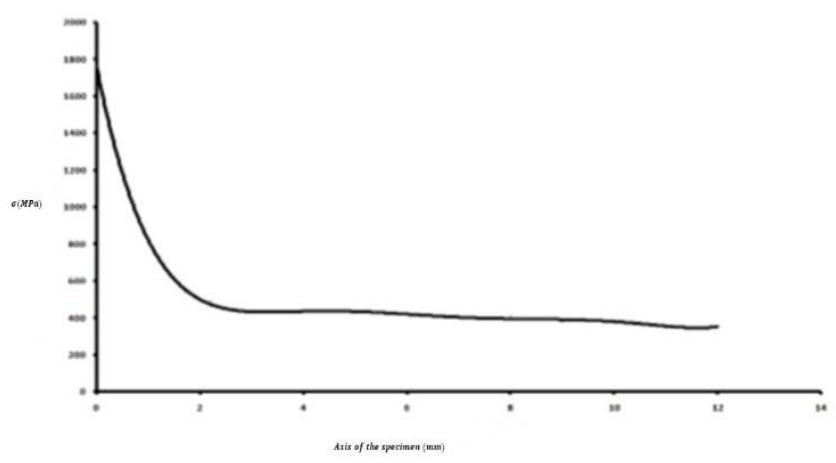

Fig.4: Evolution of the numerical stress along the horizontal axis of the specimen, $\Delta \sigma=352 \mathrm{MPa}$.

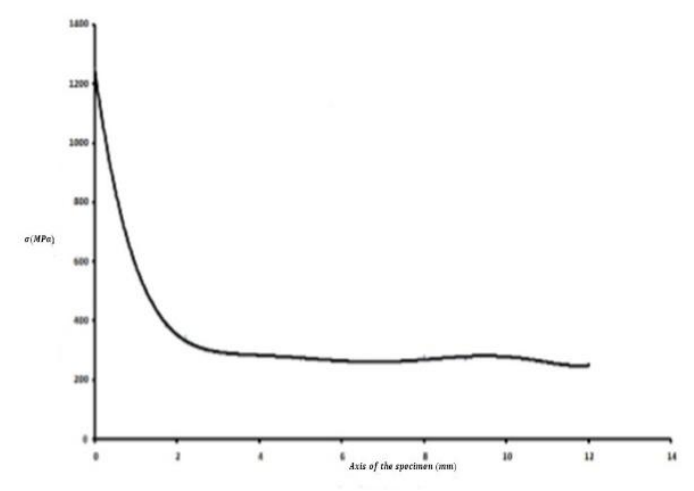

Fig.5: Evolution of the numerical stress along the horizontal axis of the specimen, $\Delta \sigma=248 \mathrm{MPa}$.

the numerical study reveals that the maximum stress is at the bottom of the notch, when at the root of the notch exceeds that of the resistance of the material (621 MPa), we observe a local rupture of connections and a crack propagation. The stress gradually decreases over the interval 0 to $2 \mathrm{~mm}$. Beyond this distance, the value of the said stress tends towards a limit value equal to the stress applied as indicated in Table 3.

D. Evolution of the stress concentration factor $(\mathrm{Kt})$ along the horizontal axis of the specimen for the two-dimensional model

The curves given in Figures (6-8) show the evolution of the numerical stress concentration coefficient along the horizontal axis in 2D for the three applied stress levels: $\Delta \sigma=$ $352 \mathrm{MPa}, 282 \mathrm{MPa}, 248 \mathrm{MPa}$.

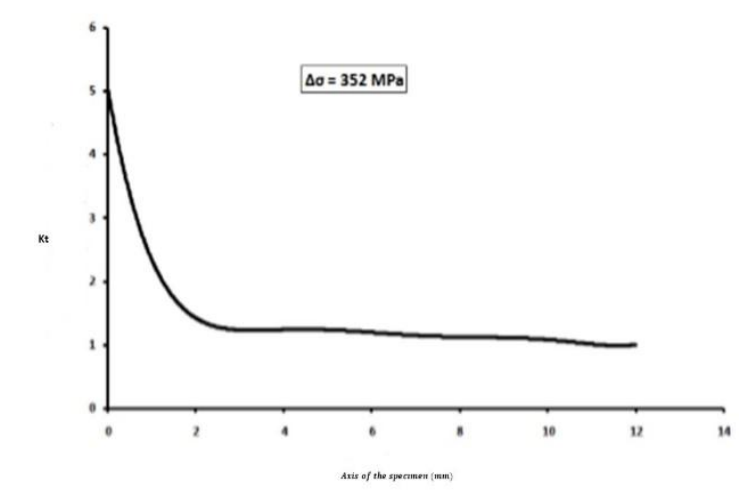

Fig.6: Evolution of the numerical stress concentration coefficient along the horizontal axis of the specimen, $\Delta \sigma=$ 352 MPa.

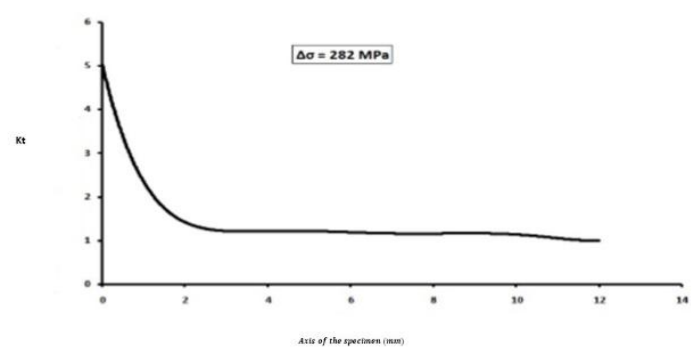

Fig.7: Evolution of the numerical stress concentration coefficient along the horizontal axis of the specimen, $\Delta \sigma=$ 282MPa.

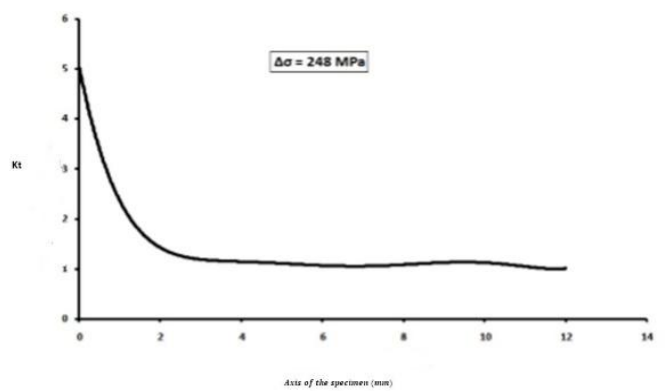

Fig. 8: Evolution of the numerical stress concentration coefficient along the horizontal axis of the specimen, $\Delta \sigma=$ 248MPa.

Published By:

Blue Eyes Intelligence Engineering \& Sciences Publication

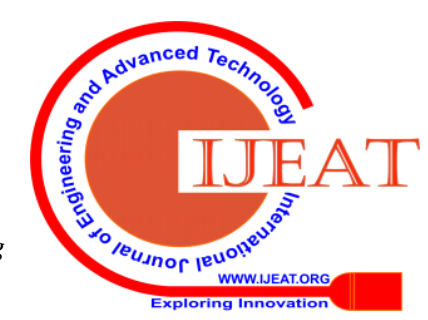


we find a drop in the value of the stress concentration coefficient Kt along the horizontal axis of the specimen, then a stabilization from $2 \mathrm{~mm}$. The value obtained for $\mathrm{Kt}$ at the bottom of the notch is maximum and is equal to 5 for the three levels of stress. This value agrees with that found experimentally [9]. The coefficient of stress concentration far from the notch tends to a limit value equal to 1 .

\section{E. Evolution of the numerical propagation velocity as a function of crack length in two dimensions}

Engineers responsible for the design of structures or items subject to loadings must not only consider the possibility of crack formation, but also evaluate their speed of propagation, to ensure that these cracks do not reach the length critical that will cause the sudden break of the piece. In this respect, they must have quantitative data that characterize the speed of propagation of a crack. When a main crack is formed, its length (or depth) increases as the number of cycles increases. The cracking rate, determined by the derivative da / dN (where $\mathrm{a}$ is the crack length and $\mathrm{N}$, the number of cycles applied), therefore increases without stopping until the final rupture of the part. Figures (9-11) show the evolution of the propagation velocity determined numerically as a function of the length of the crack in $2 \mathrm{D}$ for the three applied stresses $(\Delta \sigma$ = $352 \mathrm{MPa}, 282 \mathrm{MPa}, 248 \mathrm{MPa}$ ).

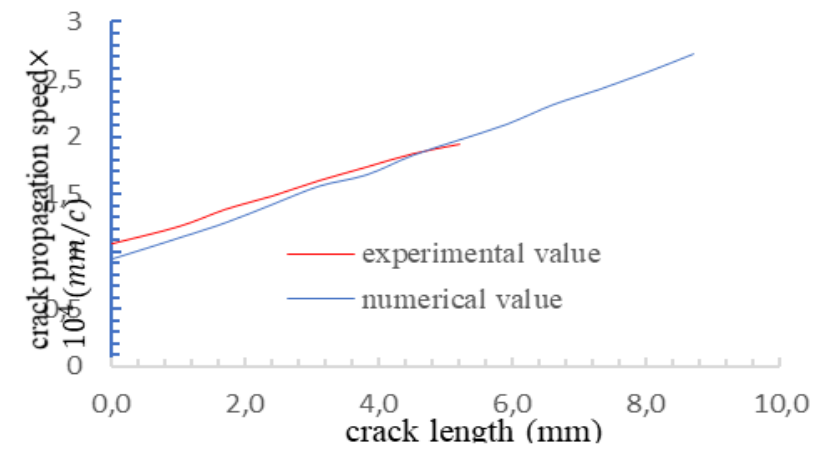

Fig. 9: The propagation velocity of crack as a function of

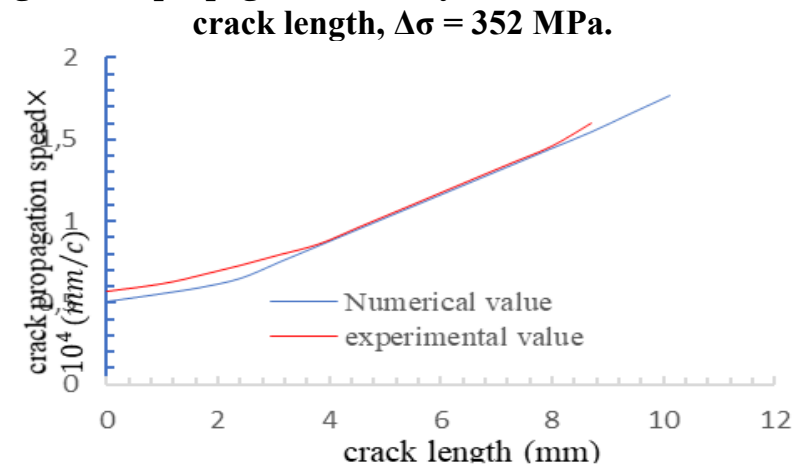

Figure 10: The propagation velocity of crack as a

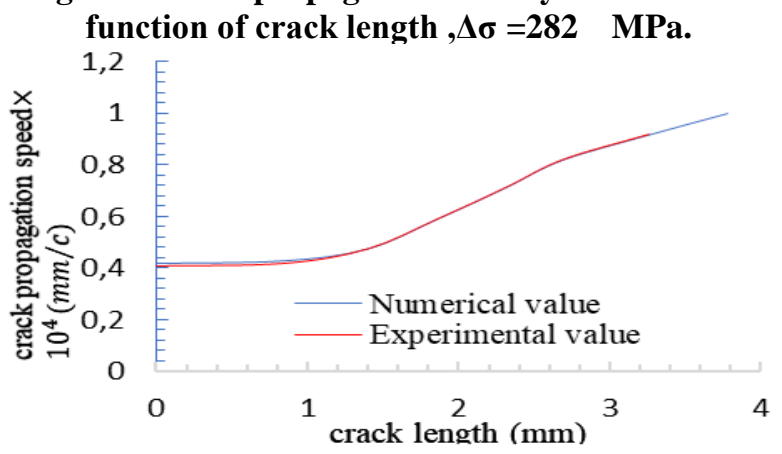

Fig.11: The propagation velocity of crack as a function of crack length, $\Delta \sigma=248 \mathrm{MPa}$.
The analysis of these results shows that there is a significant increase in the cracking rate as a function of the length of the crack and the stress applied. Our finite element results, for each constraint, are compared with those of the experiment [9]. We thus obtained a good concordance with the experimental results which makes it possible to validate our numerical model.

Cracking is generally described by the following three macroscopic stages:

a) - Stage I (propagation speed less than 10-5 mm / c)

b) - Stage II (propagation speed is between 10-5 and 10-3 $\mathrm{mm} / \mathrm{c}$ )

c) - Stage III (rapid propagation leading to sudden rupture greater than $10-3 \mathrm{~mm} / \mathrm{c}$ ).

The analysis of the curves in figures 9-11 shows that:

* At a low stress level $(\Delta \sigma=248 \mathrm{MPa})$, the cracking rate is practically between $3.85 \times 10-5$ and $3.5 \times 10-4$ mm / c, which corresponds mainly to the end of stage I of propagation.

* At a mean stress level $(\Delta \sigma=282 \mathrm{MPa})$, the cracking velocity is located in the zone 5,67x10-5 and 3,642x10-4 mm / c which corresponds to stage II of propagation and beginning of stage III.

* At a high level of stress $(\Delta \sigma=352 \mathrm{MPa})$, the cracking rate is in the range $1.11 \times 10-4$ and $3.986 \times 10-4 \mathrm{~mm} / \mathrm{c}$ propagation is mainly in stage II.

F. Evolution of the variation of the numerical stress intensity factor as a function of crack length in 2 dimensions

Figures (12-14) show the evolution of the numerical stress intensity factor (SIF) as a function of the length of the crack in $2 \mathrm{D}$ for the three applied stresses $(\Delta \sigma=352 \mathrm{MPa}, 282 \mathrm{MPa}$, $248 \mathrm{MPa})$.

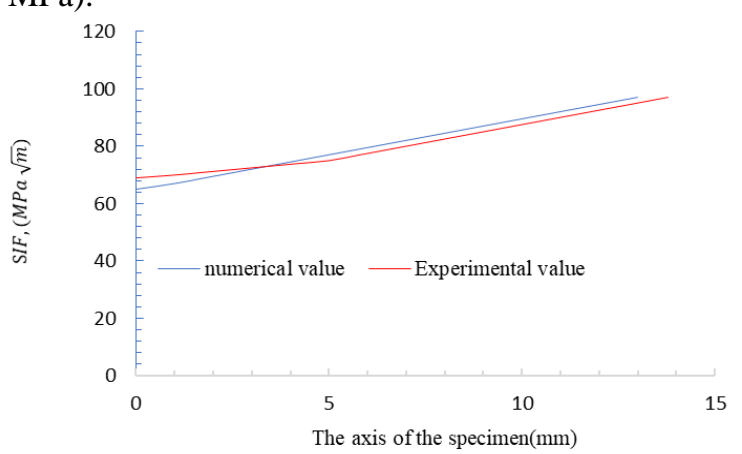

Fig.12: Evolution of the variation of the stress intensity factor as a function of the crack length, $\Delta \sigma=352 \mathrm{MPa}$.

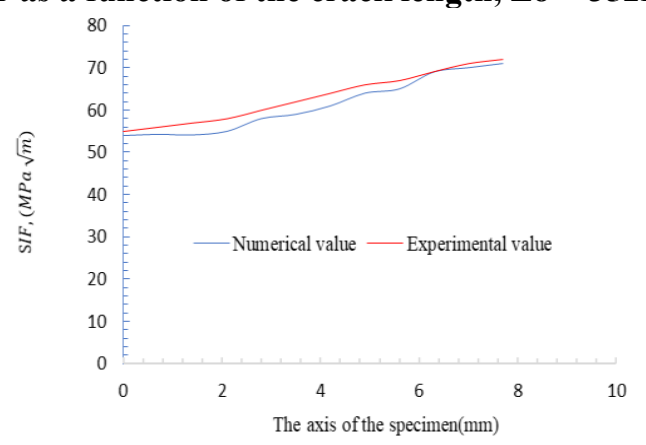

Fig.13: Evolution of the variation of the stress intensity factor as a function of the crack length, $\Delta \sigma=282 \mathrm{MPa}$

Published By:

Blue Eyes Intelligence Engineering

\& Sciences Publication

(C) Copyright: All rights reserved. 


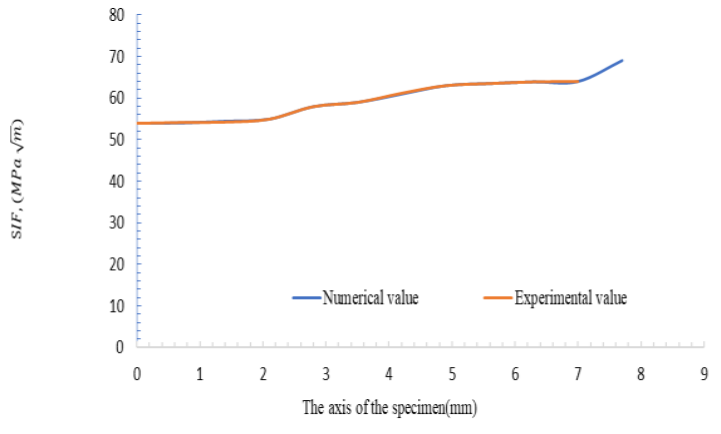

Fig.14: Evolution of the variation of the stress intensity factor as a function of the crack length, $\Delta \sigma=248 \mathrm{MPa}$

Analysis of the curves in Figures (12-14) shows that there is a significant increase in stress concentration factor as a function of crack length and applied stress. Our finite element results for each constraint are compared with the experiment [2]. We get a good match.

III .6. Evolution of the numerical propagation velocity as a function of the variation of the stress intensity factor in two dimensions

Figures (15-16) show the evolution of the logarithm of numerical stress numerical stress velocity versus log length of crack for the three applied stresses $(\Delta \sigma=352 \mathrm{MPa}, 282$ $\mathrm{MPa})$.

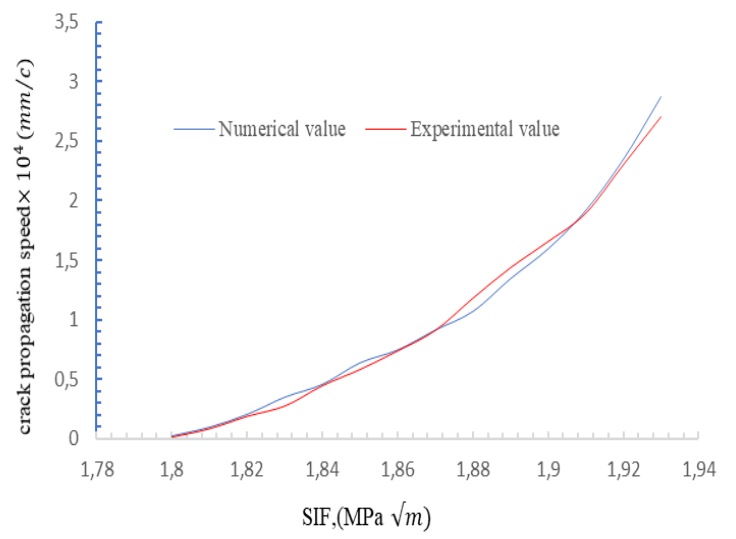

Fig.15: The propagation velocity of the crack according to the stress intensity factor, $\Delta \sigma=352 \mathrm{MPa}$

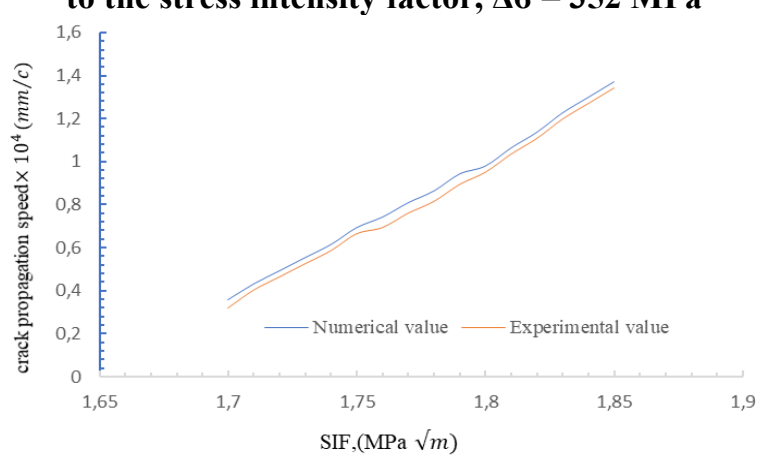

Fig.16: The propagation velocity of the crack according to the stress intensity factor, $\Delta \sigma=282 \mathrm{MPa}$

The analysis of the curves shows that even if the load is varied, it is found that the representative points of the propagation velocity as a function of $\Delta K$ are located on the same straight line (linear part).

it is the regime 2, called regime of Paris, the speed of cracking obeys the relation of Paris; there is progressive acceleration of the cracking speed when the value of the stress intensity factor approaches the critical value KIc value at which there is sudden rupture of the test specimen.

\section{CONCLUSION}

This study has used several branches of mechanics ranging fracture mechanics and the finite element method which has become unavoidable at present given its power for solving complex problems, hence the integrity of our approach. We approached the finite element numerical modeling using the Cast $3 \mathrm{~m}$ software, we considered a test specimen with double S355 steel notches, stressed in tension, causing crack opening with two planes of symmetry. The refinement of the mesh is carried out at the bottom of the notch using the elements of Barsoum. The concordance of the numerical values obtained with the experimental values, validates our numerical study.

The analysis of the results shows that the numerical value of the stress concentration coefficient Kt for the applied stresses coincides with Kt found experimentally whose value lies between 4 and 5 .

The maximum stress $\sigma$ Max is localized in the vicinity of the notch The local stress $\sigma x$, parallel to the axis of the notch, is zero at the root of the notch; on the other hand, it reaches its maximum value at a distance of $1.15 \mathrm{~mm}$ from the root of the notch along the $\mathrm{x}$ axis. The analysis of the results in terms of propagation velocity as a function of the stress intensity factor, shows two domains of behavior. A first linear domain where the

Paris law is well verified; In the second domain we lose the linearity of the $\log (\mathrm{da} / \mathrm{dn}$ ) function as a function of $\log$ $(\Delta \mathrm{K})$.

\section{REFERENCES}

1. Jhouda Salmi, Khalid El Had, Hanan El Bhilat, Abdelilah Hachim Numerical Analysis Of The Effect Of External Circumferentia Elliptical Cracks In Transition Thickness Zone Of Pressurized Pipes Using Xfem, J. Appl. Comput. Mech., 5(5) (2019) 861-874 Doi: 10.22055/Jacm.2019.28043.1452

2. A. SAFFIH, S. HARIRI, Numerical study of elliptical cracks in cylindrers with a thickness transition, International Journal of Pressure Vessels and Piping, Vol 83, N¹, pp 35-41, 2006.

3. A. EL HAKIMI, Etude numérique et expérimentale de la nocivité des défauts dans des coques cylindriques et sphériques sous pression, Mémoire de thèse doctorat d'université de technologie de Compiègne 30 Juin 2006.

4. T.H. TOPPER, M.H. HADDAD, Fatigue strength prediction of notches based on fracture thresholds, 1st int. Conf, Stockholm, Vol2, EMAS Warley ,U.K,pp 777-797,1981.

5. RAHMAN, BRUST,Approximate methods for predicing J-integral of a circumferentially surfacecracked pipe subject to bending, International Journal of Fracture, Vol 85, 1997, P: 111-130.

6. Http://www-cast3m.cea.fr/

7. A. Hachim, Etude numérique et validation expérimentale des mécanismes d'endommagement et de fissuration de l'acier S355: application aux équipements sous pression, Mémoire de thèse doctorat, Faculté des Sciences-Aïn Chock,Casablanca, 27/04/2013.

8. PETERSON R. E., stress concentration factor, Jhon Wiley and Son New York, 1974

9. M.El GHORBA, Evolutions du dommage et de la propagation de la fissure sous chargement cyclique de l'acier A36 et l'aluminium 6351-T6 , mémoire de maître et science appliqué (école polytechnique de Montréal 1985). 


\section{AUTHORS PROFILE}

Dr. Siham Ouhimmou, Phd in mechanical Engineering, Associate Professor, Department of physics, University Hassan II, Faculty of Sciences Ain Chock - Casablanca - Morocco.

Hachim Abdelilah, Professor of Higher Education at the Higher Institute of Maritime Studies. Doctor in physics and mechanics. He published several articles in the fields of pressure equipment and materials science.

Salmi Houda, PhD student in physics and mechanic,

industrial engineering and temporary professor. She published several articles in the fields of pressure equipment and the analysis of the crack propagation with XFEM.

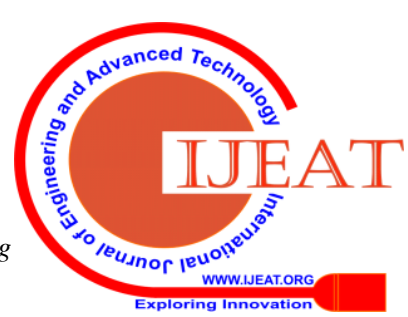

